Article

\title{
An Integrated Approach to Study Spatial Patterns and Drivers of Land Cover Within Urban Functional Units: A Multi-City Comparative Study in China
}

\author{
Hua-Feng Wang ${ }^{1,2}{ }^{\circledR}$, Xia-Lan Cheng ${ }^{1}$, Mir Muhammad Nizamani ${ }^{1}{ }^{\circledR}$, Kelly Balfour $^{3}$, \\ Liangjun Da ${ }^{2}$, Zhi-Xin Zhu ${ }^{1}$ and Salman Qureshi ${ }^{4, *(D)}$ \\ 1 Hainan Key Laboratory for Sustainable Utilization of Tropical Bioresources, School of Life and \\ Pharmaceutical Sciences, Hainan University, Haikou 570228, China; hfwang@hainanu.edu.cn (H.-F.W.); \\ chengxialan@hainanu.edu.cn (X.-L.C.); mirmuhammadnizamani@hainanu.edu.cn (M.M.N.); \\ 992982@hainanu.edu.cn (Z.-X.Z.) \\ 2 Shanghai Key Lab for Urban Ecological Processes and Eco-Restoration, School of Ecological and \\ Environmental Sciences, East China Normal University, Shanghai 200041, China; ljda@des.ecnu.edu.cn \\ 3 Department of Biology, Algoma University, Sault Sainte Marie, ON P6A 2G4, Canada; kbalfour@algomau.ca \\ 4 Department of Geography, Humboldt University of Berlin, Rudower Chaussee 16, 12489 Berlin, Germany \\ * Correspondence: salman.qureshi@geo.hu-berlin.de
}

Received: 14 May 2020; Accepted: 7 July 2020; Published: 9 July 2020

\begin{abstract}
Understanding the factors that drive green space composition and richness in heterogeneous urban landscapes is critical for maintaining important ecosystem services and biodiversity. Few studies have been conducted on urban greening and plant diversity at the urban functional unit (UFU) level, although a handful of studies have explored the drivers of greening percentage and its relationships with plant richness in tropical cities. In this study, we conducted field surveys, compiled census and remote sensing data, and performed spatial analyses to investigate the interrelationship between greening percentages, plant diversity, and the socioeconomic variables of different primary and secondary UFUs in the cities of Beijing, Zhanjiang, and Haikou in China. We found that these relationships did not differ significantly between primary and secondary UFUs, and that Parks represented the largest areas of forested land, grassland, and water bodies across all three cities. Moreover, the greening percentages of all UFUs across these three cities were positively correlated with both socioeconomic variables and plant species richness. These relationships can be utilized to guide future green space planning within urban ecosystems.
\end{abstract}

Keywords: plant diversity; remote-sensing images; socioeconomic; socio-ecological complexities; urban ecology; tropical area; urban green space; urban greening

\section{Introduction}

As the "green lung" of urban ecosystems [1], vegetation plays an irreplaceable role in the urban ecological environment as well as in the social functioning and well-being of the human population [2-5]. The structure of urban green space determines its ability to provide ecosystem services and functions, such as food production and erosion protection [6]. Understanding the relationship between urbanization intensity and the structure and attributes of urban green space is the central topic of urban ecological and biodiversity conservation. This is also an urgent task for modern cities aiming to optimize infrastructure and protect the urban ecological environment $[1,7]$, which is conducive to maximizing the function of ecological services and designing suitable urban green infrastructure [4]. Exploring the coupling mechanism between urban plant diversity and both socioeconomic and natural environmental factors will aid our understanding of the spatiotemporal variation of urban vegetation patterns and the evolution of urban 
ecosystems. Additionally, this will provide the theoretical basis and scientific support for understanding the interaction between human social and economic activities and the urban ecological environment [8-10].

To provide scientific suggestions for the sustainable development of tropical coastal cities in China, we must strengthen our understanding of plant diversity variation across urban ecosystems as well as the driving mechanisms of this variation within different tropical cities. Urban functional units (UFUs) are ideal models for analyzing the components of urban ecosystems and powerful grippers for uncovering complex and highly heterogeneous urban ecosystem structures. A UFU is a physical space with a defined boundary within an urban area (e.g., a park, school, residential area, road, etc.), and is utilized by humans to perform a specific function, such as education, transportation, or residency. UFUs have also been called urban structure units [10-13]. At different levels of social and economic development, the study of urban vegetation patterns combines both natural and anthropogenic factors to reveal the mechanisms responsible for vegetation pattern variation between different UFUs [14-16]. Groffman et al. [17] studied the composition of land cover, landscape structure, and ecosystem functions in six major cities in the United States (Miami, Baltimore, Boston, Minneapolis, Sao Paulo, and Los Angeles), and found that biological homogenization extends to the structure and function of ecosystems (continental scale, carbon dynamics, and microclimate) from the regional to the continental scale. Although the structure of China's urban green space is somewhat similar to other countries around the world, it is more fragmented and less discrete than that of other countries [6]. Thus, the quantitative mechanism of environmental factors and management measures on urban vegetation remains unclear [18]. Da et al. [19] proposed "learning from nature" through the "different age compound deciduous-evergreen mixed forest" urban landscape construction model; this model was implemented in Shanghai Pudong for the construction of the Shanghai Urban Landmark plant community, which has provided guidance and reference for similar greening projects in the country. Zhang et al. [4] recommended improving the service function of urban forests by increasing the average fractal dimension, thereby maintaining the aggregation and proximity of forest patches.

There are three shortcomings regarding UFU-based studies: firstly, only a few studies have been conducted at the UFU level within cities across China as a means of studying urban vegetation patterns; secondly, few studies have compared variations within different UFU types between the rapidly urbanizing inland cities and tropical coastal cities; thirdly, fewer studies have explored the drivers of greening percentage and their relationship with plant richness at the UFU level [10-13]. We address these shortcomings through this study.

We coupled remote sensing interpretation with field investigation, and obtained the land-use statuses of UFUs in the suburban gradients of three cities in China: Beijing, Haikou, and Zhanjiang. The spatial patterns of green patches in all UFU types were analyzed using data pertaining to the socioeconomic characteristics of the area. We searched for a correlation between land use and green space characteristics across different UFUs as well as social and economic factors, such as population density, maintenance practices, and housing prices. We also determined the influence of urbanization, as reflected by increases in population density and building floor proportion, on land use and the patterns of urban green space within different UFU types. We mapped and quantified the land cover patterns of UFUs in Beijing, Zhanjiang, and Haikou with SPOT 5 (Satellite Pour 1'Observation de la Terre) [20] images taken in 2010. In this study, we aimed to (1) dynamically map the spatial extent of urban land cover across different primary and secondary UFUs; (2) compare the greening percentages of different UFUs and identify possible drivers; and (3) analyze the relationships between greening percentages and species richness across different UFUs within Beijing, Zhanjiang, and Haikou.

\section{Materials and Methods}

\subsection{Field Survey and Sampling Settings}

A combination of mesh sampling and random sampling comprising field surveys for urban vegetation, UFU types, and a socioeconomic questionnaire were completed in Haikou, Zhanjiang, 
and Beijing $[10,13,21]$. After selecting the sampling areas, a kilometer grid was used to divide the city into several uniformly sized lattices. Mesh sampling was used to ensure that urban vegetation was sampled uniformly within each of the three cities. The comprehensive consideration of all UFU types in the grid ensured that all urban sampling points were represented. This sampling method combined the uniformity and representativeness of samples, which can better reflect the basic characteristics of urban green space; however, the use of random sampling led to the abandonment of certain sample sites, such as those located on impervious surfaces, large areas of water, or in unreachable regions. The completion of sampling in urban areas is subject to restrictions and obstacles; for example, the landowners often denied us access to private UFUs. Moreover, randomly selected regions often have large areas that are covered with some impervious surface or water, thus making plant sampling impossible or meaningless. Such restrictions and obstacles were present, so we were unable to use strictly stratified random sampling, which would have been desirable. We therefore adopted a purposive sampling method based on Wang et al. [13].

To include sites that represented the distribution of socioeconomic variables in Beijing, we applied the following procedure, which has key elements of iterative random sampling [10]. Two scenes of cloud-free SPOT 5 (Satellite Pour 1'Observation de la Terre) images of the urban area of Haikou (north of Haikou West Line) for the year 2010 were obtained. These images were divided into $1902 \times 2 \mathrm{~km}$ grids $[10,13,22]$ according to the probability theory of double density mosaic stratified sampling, which proposes a 3:1 sampling density in urban areas and suburbs [23]. A comprehensive analysis was completed to determine the UFU types within each grid. To make the repeated set-up of plant sampling at each location easier, each long-term observation sampling area was assigned one or more markers, such as buildings, as well as GPS positioning and topographic map marking - detailed records of these data were kept. Based on the American Urban Forestry classification [24], we selected hundreds of UFUs within each city to ensure that the sampling areas were equally represented.

The same standard was used to determine the urban and rural gradient division of Haikou and Zhanjiang. The classification criteria for urban areas and suburbs were determined according to the proportion of impervious area in the sample site: the impervious rate was $67-100 \%$ for urban areas, $34-66 \%$ for the suburbs, and 34\% for non-urban areas [25]. Three sides of Haikou and Zhanjiang were covered by the sea (Figure 1C,D).

\subsection{Remote Sensing Interpretation of Land Cover Type}

The urban greening percentage was calculated by dividing the total areas of forest, mixed forest and herb, and herb by the total area of each UFU. A suitable land cover classification system developed by Cadenasso et al. [26] was applied for the identification of land cover levels from SPOT 5 images. Land use/land cover maps for the study areas were derived using the object-based image analysis (OBIA) method. Two SPOT image scenes were obtained for each city from August 30 (all) as well as October 12 (Haikou), October 23 (Zhanjiang), or October 25 (Beijing) of 2010 (four colors banded; $10 \mathrm{~m}$ resolution) - these were used as the primary source for land use and land cover (LULC) classification. We performed multi-resolution image segmentation to generate image objects to which the classification algorithm could be applied. For this segmentation, we used a scale 'parameter' of 20, which was determined by the visual interpretation of the segmentation results. An important result of the segmentation process was the identification of uniform objects and features that could be used for classification (e.g., spectral values, shapes, textures, etc.) [27]. Once segmentation was achieved, we used a combination of fuzzy rules and standards nearest neighbor (SNN) algorithms to classify each image object. We selected more than 100 training samples and reference assistance data including digital topographic maps, field survey data, high spatial resolution image $(\mathrm{QB})$, and Google Earth to identify their representative classes. Based on the spectral and spatial information of these samples, we created SNN feature space and fuzzy rule algorithms for classification. Each image object was assigned a probability of the LULC class to which it belonged, and the final image object class was determined based on which class had the highest probability. Finally, we refined the classification by manual adjustment to improve the overall quality. As a result, six categories were identified using the Definiens 7.0 software: exposed land, open waters, forests, high-density cities, 
low-density cities, and farmland. Classification accuracy was assessed by comparing the reference collection with the classified image [28]. Based on the confusion matrix, the overall accuracy of the land cover classification was $94.42 \%$ with a Kappa coefficient of 0.94 . By employing the LULC map, we further determined the percentage of each LULC type in each UFU in ArcGIS 10 (ESRI).

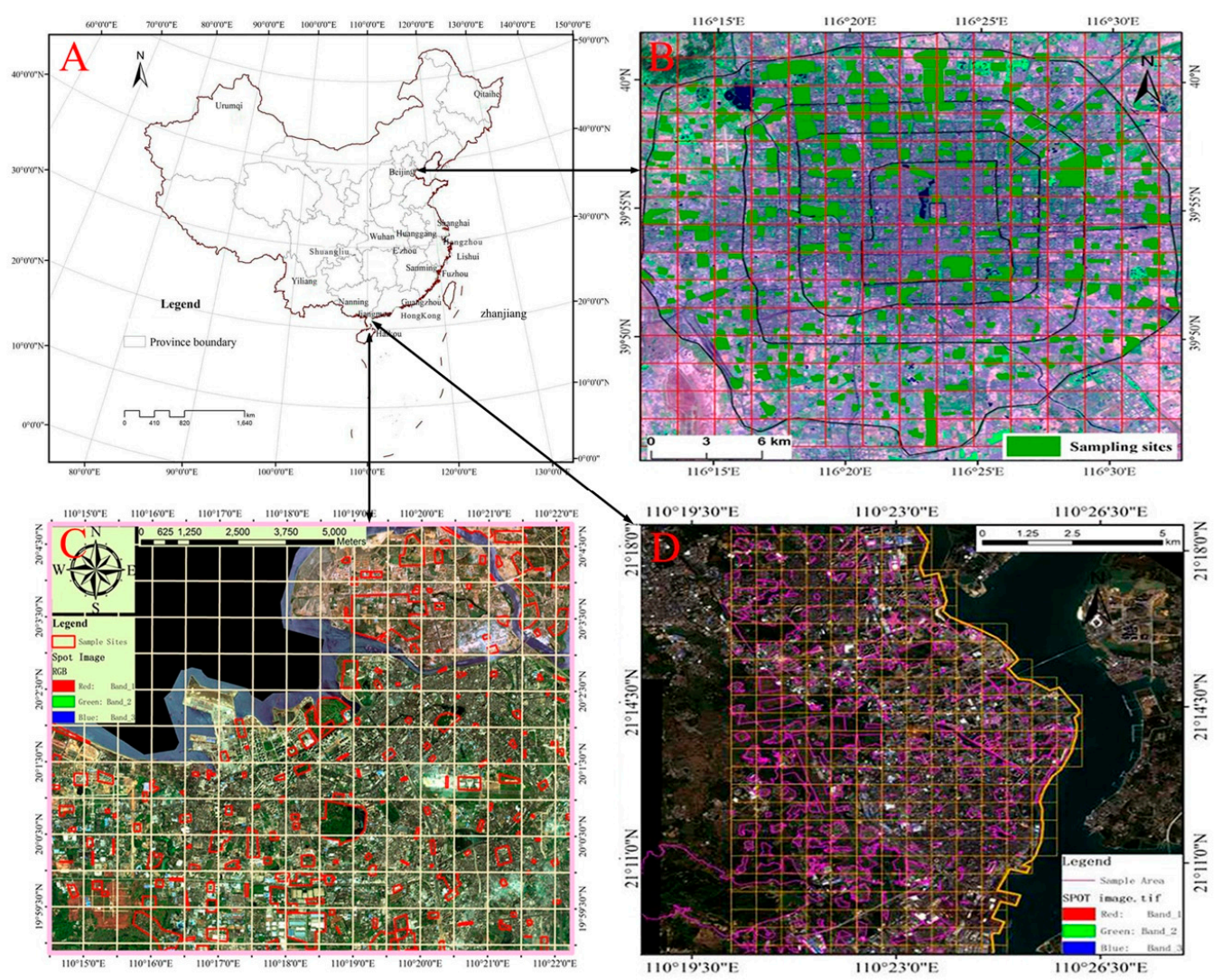

Figure 1. Satellite images showing the locations of the study sites (A) as well as the sampling area within the cities of Beijing (B); cited from Wang et al. [10,13], two scenes of cloud-free SPOT 5 (Satellite Pour l'Observation de la Terre) images with spatial resolution of $10 \mathrm{~m}$ and acquisition dates of 30 August and 25 October 2002), Haikou (C); cited from Zhu et al. [11], Satellite Pour l'Observation de la Terre) with a spatial resolution of $10 \mathrm{~m}$ (accessed in October 2010) and Zhanjiang (D); cited from Cheng et al., under review; One Spot 193 image of our study area (November 27th, 2016) with a resolution of $1.5 \mathrm{~m}$ was interpreted in order to assess the ground cover of each UFU).

There is a time difference between these remote sensing and socio-economic data, but this is also the case in similar studies $[29,30]$. Due to limitations with our funding, we were not able to obtain 2017/18 SPOT remote sensing data for the three cities, and socio-economic data were not available for hundreds of UFUs within Beijing, Haikou, and Zhanjiang for the year 2002. We decided to identify correlations between SPOT in different years (see legend of Figure 1) and socio-economic data in 2017/2018 for the same UFUs.

\subsection{Field Vegetation Survey}

A stratified sampling method was used to complete vegetation surveys within each UFU. We investigated trees, shrubs, and herb layers in each UFU, and randomly selected a sampling point in each layer. If the trunk of an individual woody plant was larger than $2 \mathrm{~cm}$ in diameter, it was considered a tree, otherwise it was classified as a shrub. We had at least three $10 \mathrm{~m} \times 10 \mathrm{~m}$ tree sampling plots within each UFU with five $2 \mathrm{~m} \times 2 \mathrm{~m}$ shrub sampling plots and five $1 \mathrm{~m} \times 1 \mathrm{~m}$ herb sampling plots nested within each tree plot. For UFUs which were highly heterogeneous (e.g., Parks) or had an area greater than 30 square kilometers, more than three tree plots were sampled. We recorded the species name, diameter 
at breast height $(\mathrm{DBH})$, height, and crown width of each tree; the species name, height, and crown width of each shrub; and the species name, height, and population size of each herb. The plant richness and density variables were calculated as follows: tree and shrub richness $=$ the total number of tree and shrub species in three $10 \mathrm{~m} \times 10 \mathrm{~m}$ tree/shrub plots for each UFU; herb richness $=$ the number of herb species in each $1 \mathrm{~m} \times 1 \mathrm{~m}$ herb plot.

\subsection{Socioeconomic Variables}

We collected data regarding the construction period, housing price, and population density of each UFU. The UFU construction period was determined by referencing the city portal or through interviews with locals of each UFU. The housing prices (yuan/square meter) within each UFU were available from the Beijing Anju website [31] with a query time from May 1, 2017 to June 1, 2018, and the average price of second-hand homes was also retrieved from this website. We obtained the average number of members (B) within each family by referring to the "China cities' Statistical Yearbook" Beijing Municipal Bureau of Statistics [32], the Guangdong Bureau of Statistics [33], and the Hainan Bureau of Statistics [34]. The population (P) of each UFU was determined as follows: $\mathrm{P}=\mathrm{B} \times \mathrm{S} \times \mathrm{M}$, permanent population density (Person $/ \mathrm{km} 2$ ) $=\mathrm{P} / \mathrm{A}$, where $\mathrm{A}$ was the area of each UFU. B is the number of members in each family. $S$ is the number of houses of each building, while $M$ is the number of buildings in the area by accessing each UFU or by referencing Google Earth images [35].

\subsection{Data Analysis}

Correlation analysis was carried out with landscape pattern index and diversity data to analyze the relationship between landscape heterogeneity and diversity, and the ecological significance of the landscape pattern index. SPSS was used to analyze the percentage of plots containing woodland, grassland, pavement, and buildings within three UFUs types. We also analyzed the relationship between land use status and spatial vegetation characteristics of UFUs (greening rate, the degree of fragmentation of green patches) and factors such as distance from city center and population density.

The different LULC types of primary and secondary UFUs in Beijing, Zhanjiang, and Haikou were assessed using the Urban Forest Effects (UFORE) Model: Field Data Collection Manual [24]. We analyzed the data by comparing the areas of land cover types (e.g., impervious area, forest land area, grassland area, and water area; Figure 2) and the greening percentages of different primary and secondary UFUs in Beijing, Zhanjiang, and Haikou; the correlation between the greening percentages of parks, schools, and residential areas and the construction period, house price, and population density of each city; and the correlation between the greening percentage of parks, schools, and residential areas and species richness of woody plant species and herbaceous species in each city.

We conducted Kruskal-Wallis tests to compare the differences between greening percentages among UFUs in each city. We used generalized linear models (GLMs) to look for associations between greening percentages and our list of predictors (Table 1). We performed backward stepwise regression using the "step" function in R [36] to select the best model with the lowest Akaike information criterion (AIC). To avoid multicollinearity of variables, we removed predictors correlated at Pearson's $r>0.7$. Construction age, the water content of the soil, green space area, wasteland area, impervious area, water area, perimeter, fertilization frequency, and watering frequency were log-transformed in order to meet the assumption of normality. All predictor variables were standardized and centered before being included in the models. 

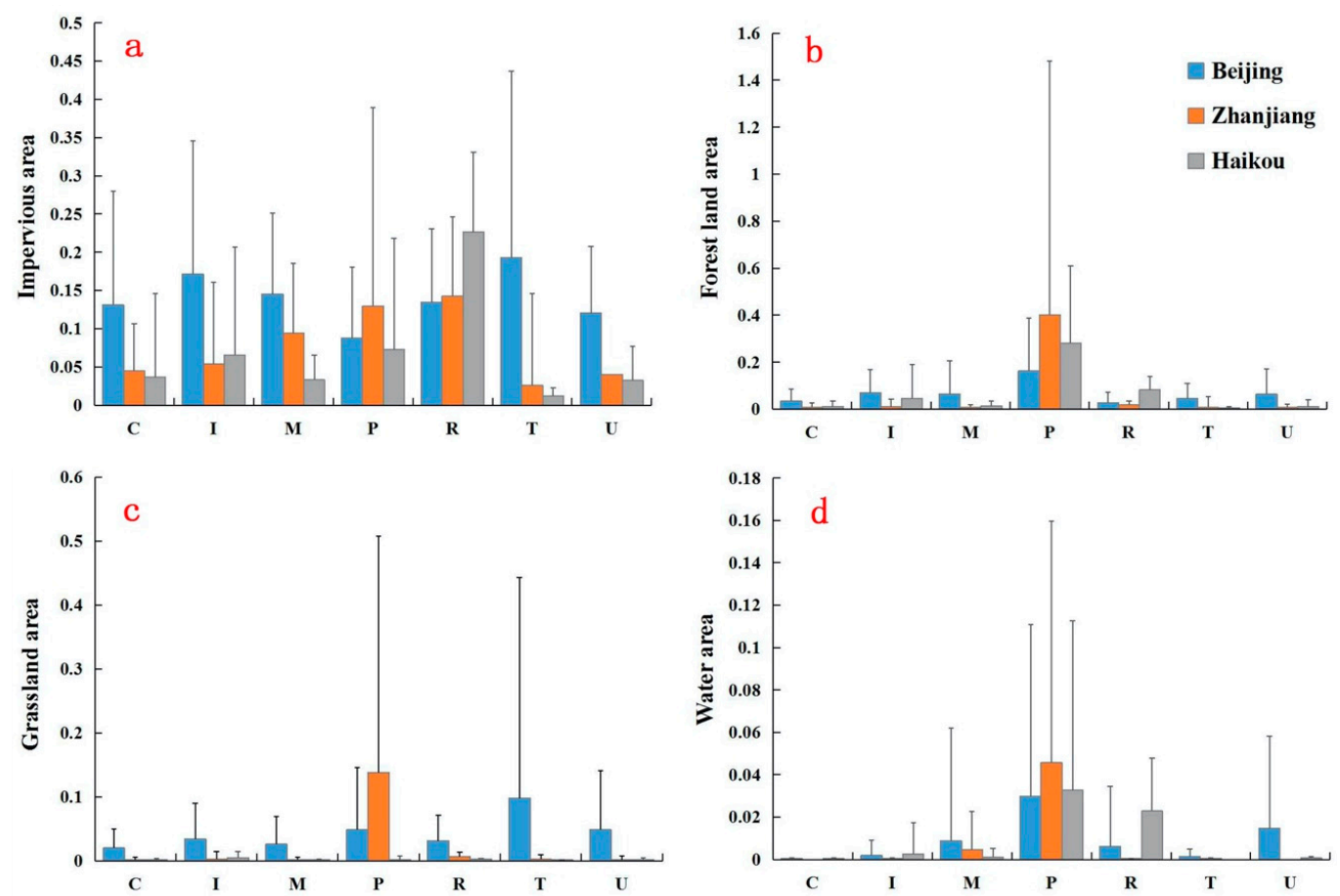

Figure 2. Areas of primary urban functional units in Beijing, Zhanjiang, and Haikou for impervious area $\left(\mathrm{km}^{2}\right)(\mathbf{a})$, forest land area $\left(\mathrm{km}^{2}\right)(\mathbf{b})$, grassland area $\left(\mathrm{km}^{2}\right)(\mathbf{c})$, and water area $\left(\mathrm{km}^{2}\right)(\mathbf{d})$.

Table 1. A summary of the predictor variables used in the analysis as well as the units and transformations associated with each.

\begin{tabular}{|c|c|c|}
\hline Variables & Units & Transformations \\
\hline \multicolumn{3}{|l|}{ Predictors } \\
\hline \multicolumn{3}{|l|}{ UFU characteristics } \\
\hline Construction age & year & $\log (x)$ \\
\hline House price & RMB (Yuan) & \\
\hline Population density & person $/ \mathrm{km}^{2}$ & \\
\hline Distance from main road & $\mathrm{g} / 100 \mathrm{~g}$ & $\log (\mathrm{x})$ \\
\hline Distance from urban center & $\mathrm{g} / 1000 \mathrm{~g}$ & \\
\hline Traffic flow & $\mathrm{km}^{2}$ & $\log (x)$ \\
\hline Longitude & decimal degrees & \\
\hline Latitude & decimal degrees & \\
\hline \multicolumn{3}{|l|}{ Land-use factors } \\
\hline Impervious area & $\mathrm{km}^{2}$ & $\log (x)$ \\
\hline Wasteland area & $\mathrm{km}^{2}$ & $\log (x)$ \\
\hline Water area & $\mathrm{km}^{2}$ & $\log (x)$ \\
\hline Perimeter & $\mathrm{km}$ & $\log (x)$ \\
\hline \multicolumn{3}{|l|}{ Human maintenance } \\
\hline Fertilization frequency/year & times/year & $\log (\mathrm{x})$ \\
\hline Pesticide frequency /year & times/year & $\log (\mathrm{x})$ \\
\hline Watering frequency/year & times/year & $\log (\mathrm{x})$ \\
\hline Weeding frequency/year & times/year & $\log (x)$ \\
\hline $\begin{array}{c}\text { Trimming frequency/year } \\
\text { Plant factors }\end{array}$ & times/year & $\log (x)$ \\
\hline Herb species richness & number of species & $\log (x)$ \\
\hline Shrub species richness & number of species & $\log (x)$ \\
\hline Tree species richness & number of species & $\log (x)$ \\
\hline Total species richness & number of species & $\log (x)$ \\
\hline Natural factors & & \\
\hline Organic matter of soil & $\mathrm{g} / 1000 \mathrm{~g}$ & $\log (x)$ \\
\hline Water content of soil & $\mathrm{g} / 100 \mathrm{~g}$ & $\log (x)$ \\
\hline Temperature & ${ }^{\circ} \mathrm{C}$ & $\log (\mathrm{x})$ \\
\hline Precipitation & $\mathrm{mm}$ & $\log (x)$ \\
\hline
\end{tabular}


We calculated Moran's I with the R package "ape" [37] to assess whether greening percentages were spatially autocorrelated. In cases where we found spatial autocorrelation (e.g., the greening percentage of Zhanjiang), we also included "latitude" and "longitude" as confounding variables in our models. Results from Moran's I test on model residuals confirmed a notable reduction in spatial autocorrelation. We chose a level of significance of $\mathrm{P}<0.05$ to reject the null hypothesis. All statistical procedures were conducted in R software v 3.5.2 (R Foundation for Statistical Computing, Vienna, AT).

\section{Results}

\subsection{The Number of Primary and Secondary UFUs Within the Three Cities}

We identified 10 primary UFU types in Beijing, the most and least numerous of which were Institutional/Cemetery $(n=63,21.58 \%)$ and Golf Course $(n=3,1.03 \%)$ respectively. We identified 31 secondary UFU types in Beijing, the most and least numerous of which were Park $(n=53,18.15 \%)$ and Nursery/ Shopping Center/Airport/Refuse Processing Plant $(n=1,0.34 \%)$, respectively (Table 2).

Table 2. The numbers and percentages of primary and secondary urban functional units within Beijing, Zhanjiang, and Haikou based on the Urban Forest Effects (UFORE) model.

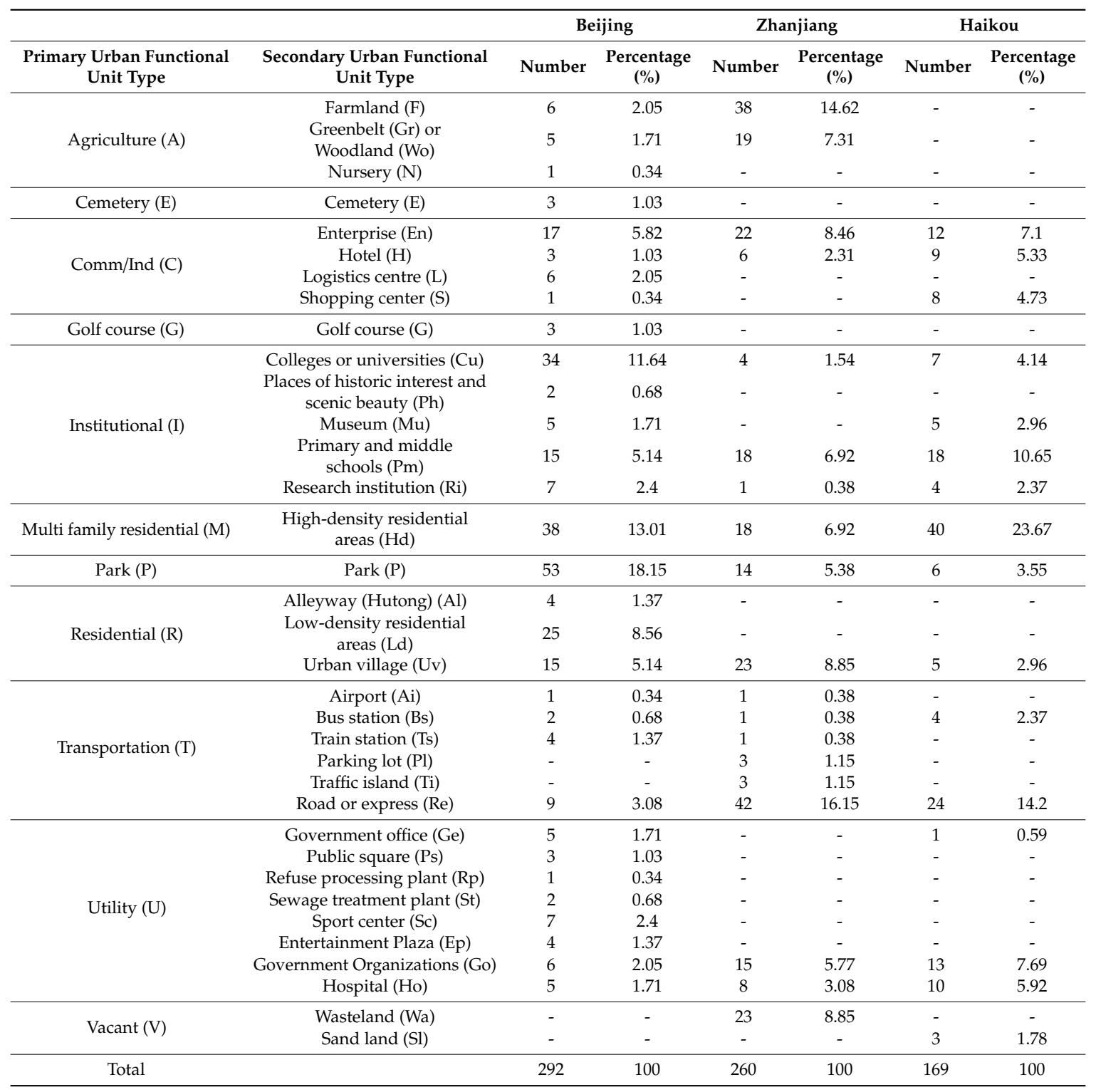


We identified nine primary UFU types in Zhanjiang, the most and least numerous of which were Agriculture $(n=57,21.92 \%)$ and Park $(n=14,5.38 \%)$, respectively. We identified 19 secondary UFU types in Zhanjiang, the most and least numerous of which were Road or Express ( $\mathrm{n}=42,16.15 \%)$ and Research Institution/Airport/Bus Station/Train Station ( $=1,0.38 \%$ ), respectively (Table 2).

We identified eight primary UFUs in Haikou, the most and least numerous of which were Multi-Residential $(n=40,23.67 \%)$ and Vacant $(n=3,1.78 \%)$, respectively. We identified 16 secondary UFUs in Haikou, the most and least numerous of which were High-Density Residential Areas ( $\mathrm{n}=40$, $23.67 \%$ ) and Government Office $(n=1,0.59 \%)$, respectively (Table 2).

\subsection{The Greening Percentages of Different UFUs}

Our results indicated that within the primary UFUs of Beijing, Zhanjiang, and Haikou, Residential areas have the most impervious surface areas while Parks have the most forest, grass, and watery land areas (Figure 2). Within the secondary UFUs of Beijing, Zhanjiang, and Haikou, Colleges/Universities have the most impervious surface area while Parks have the most forest, grass, and watery land areas (Figure 3). Mean greening percentage was greatest in Parks for all three cities, with Haikou having the highest greening percentage overall $(90.31 \pm 5.1)$. The greening percentage of Parks was significantly higher than the other primary UFU types within Beijing and Haikou $(t$-test, $p<0.01)$. Transportation area has the lowest greening percentage in both Beijing and Haikou, while Commercial area had the lowest greening percentage in Zhanjiang. The lowest greening percentage overall was in the Transportation area $(10.33 \pm 4.3)$ in Haikou (see boxplot Figures 4 and 5).
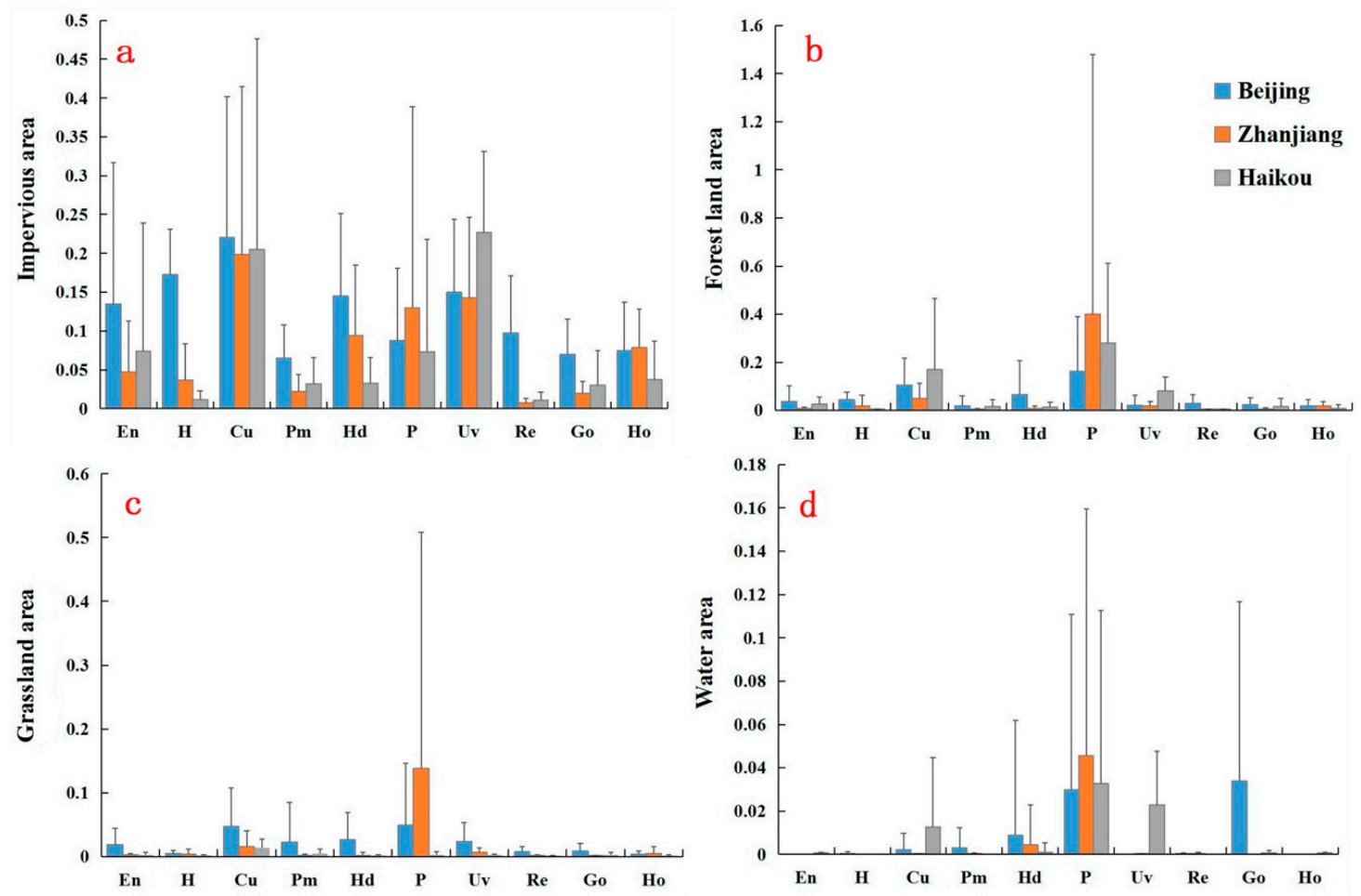

Figure 3. Areas of secondary urban functional units in Beijing, Zhanjiang, and Haikou for impervious area $\left(\mathrm{km}^{2}\right)(\mathbf{a})$, forest land area $\left(\mathrm{km}^{2}\right)(\mathbf{b})$, grassland area $\left(\mathrm{km}^{2}\right)(\mathbf{c})$, and water area $\left(\mathrm{km}^{2}\right)(\mathbf{d})$. 

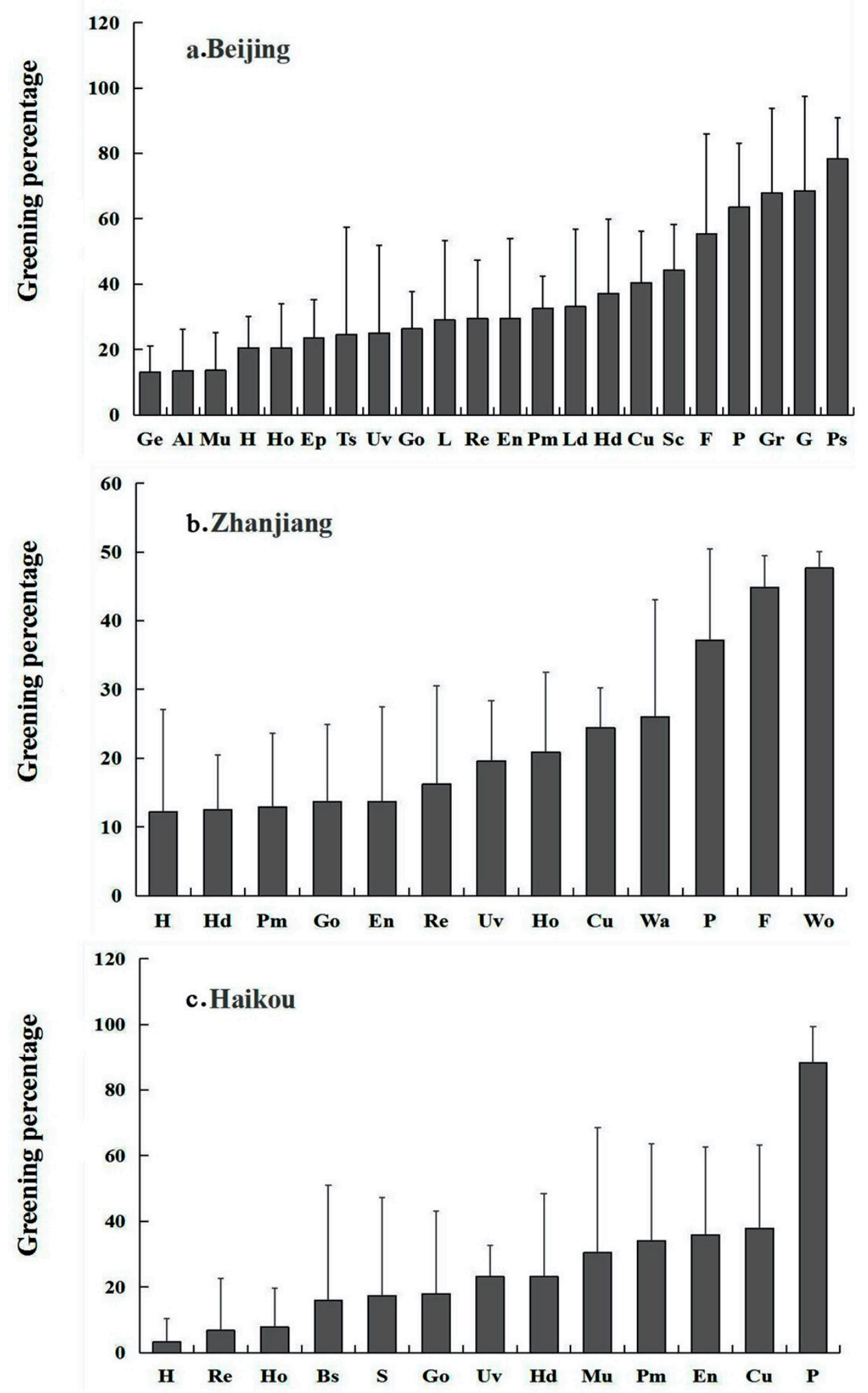

Figure 4. Greening percentages of different secondary urban functional units within Beijing (a), Zhanjiang (b), and Haikou (c). 


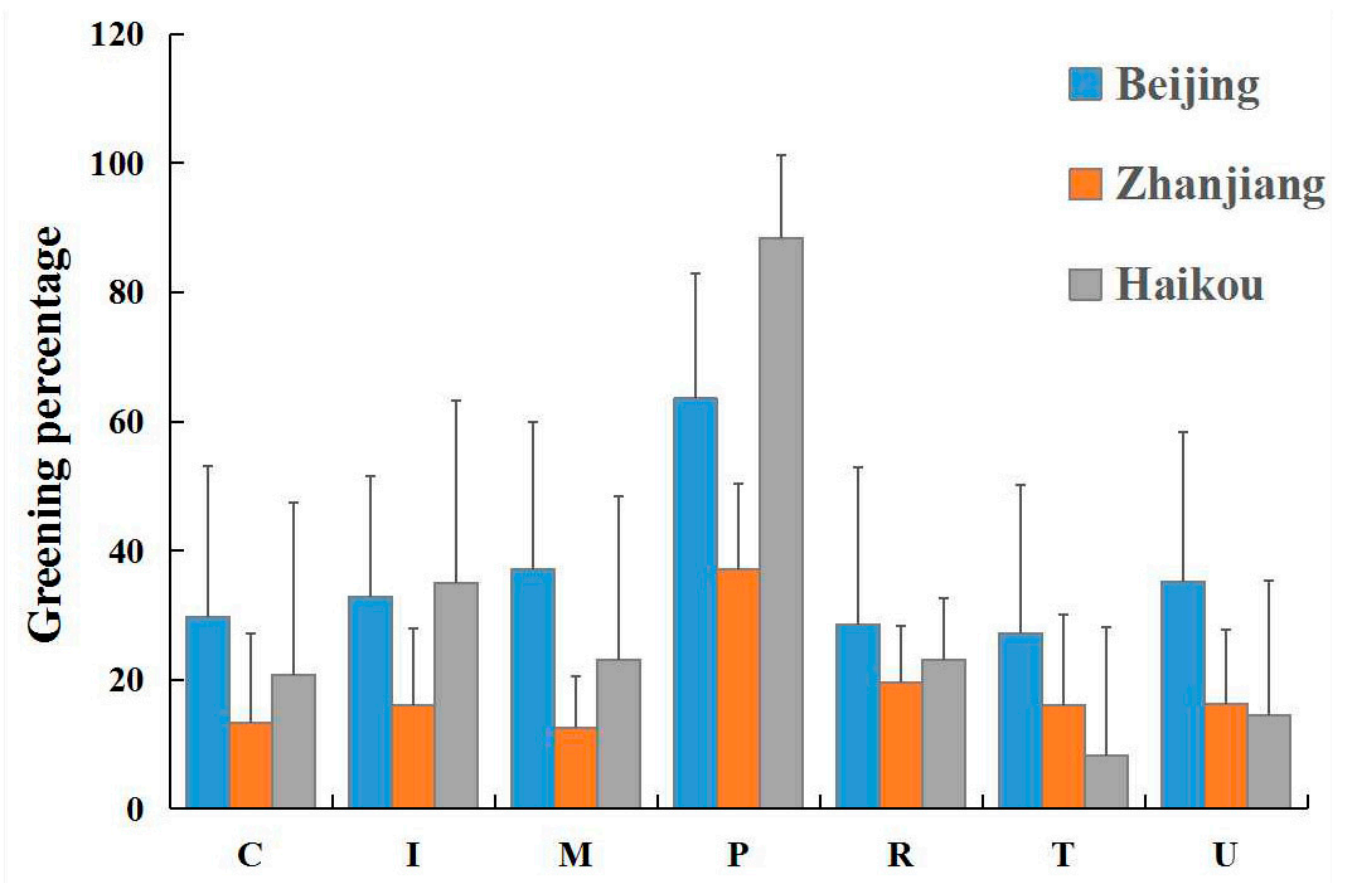

a. Primary urban functional units

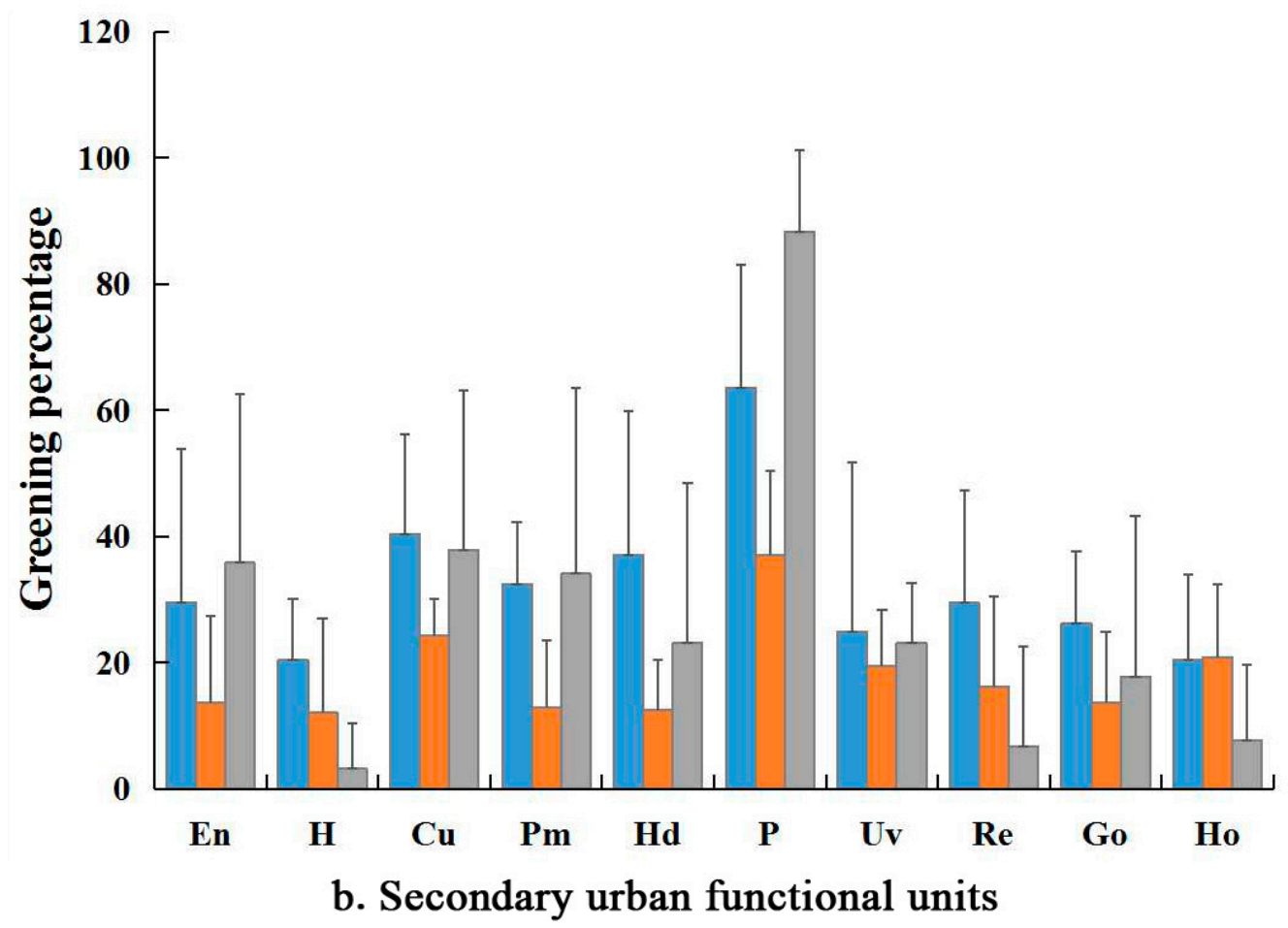

Figure 5. Greening percentages of both primary (a) and secondary (b) urban functional units found within Beijing, Zhanjiang, and Haikou.

3.3. Greening Percentages of Different UFUs Across Three Cities Correlated with Socioeconomic Variables and Species Richness

The greening percentages of Parks in Beijing, Zhanjiang, and Haikou were positively correlated with socioeconomic variables and species richness $\left(R^{2}=0.893-0.188, p<0.05\right)$ (Figure 6). The greening percentages of School areas in Beijing, Zhanjiang, and Haikou were positively correlated with socioeconomic 
variables and species richness $\left(\mathrm{R}^{2}=0.573-0.23, p<0.05\right)$ (Figure 7). The greening percentages of Residential areas in Beijing, Zhanjiang, and Haikou were positively correlated with socioeconomic variables and species richness $\left(R^{2}=0.624-0.23, p<0.05\right)$ (Figure 8 ).
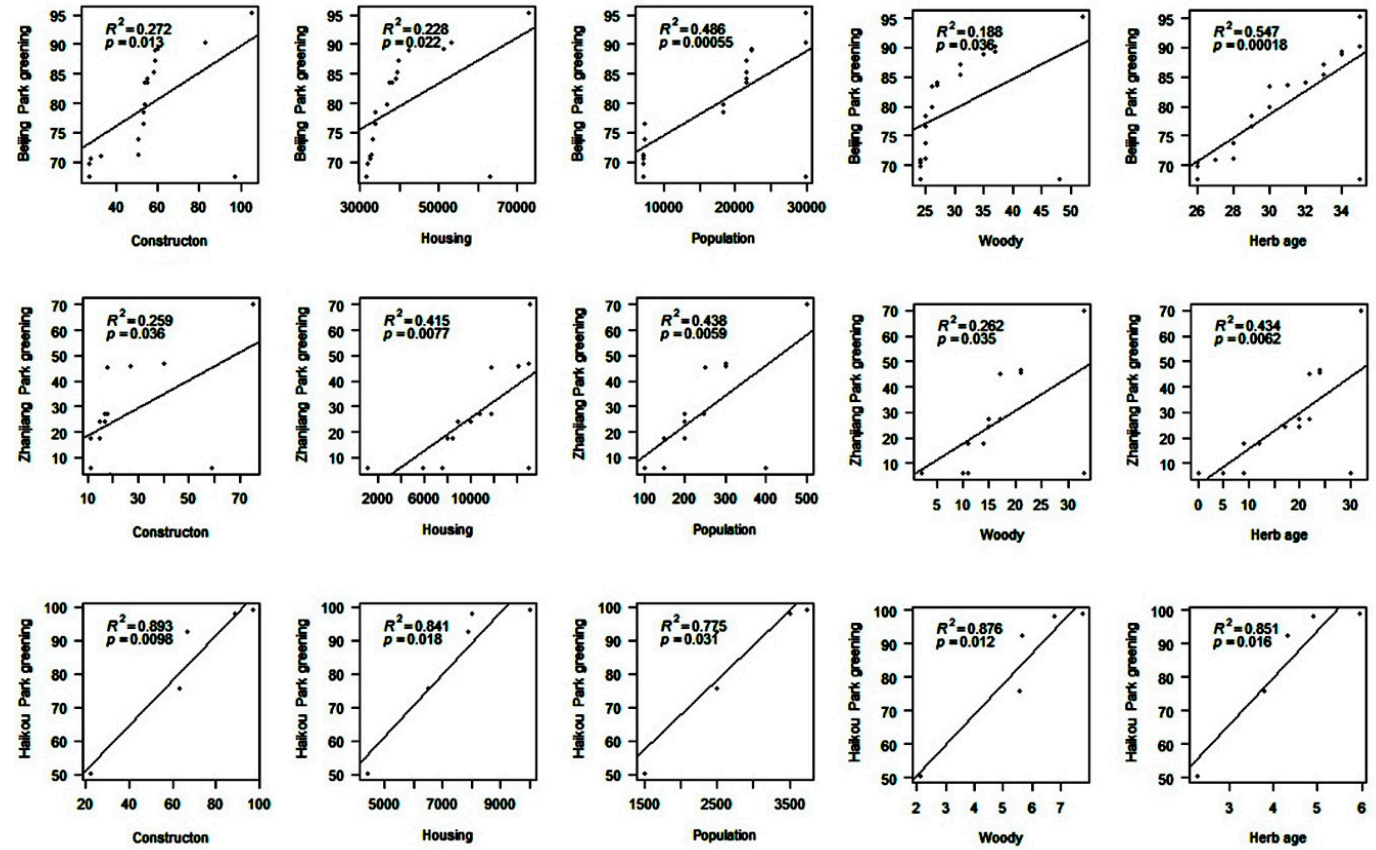

Figure 6. Scatterplots depicting the relationships between the greening percentages of Parks and both socioeconomic variables (construction age, housing price, and population density) and species richness (woody and herbaceous) within Beijing, Zhanjiang, and Haikou.
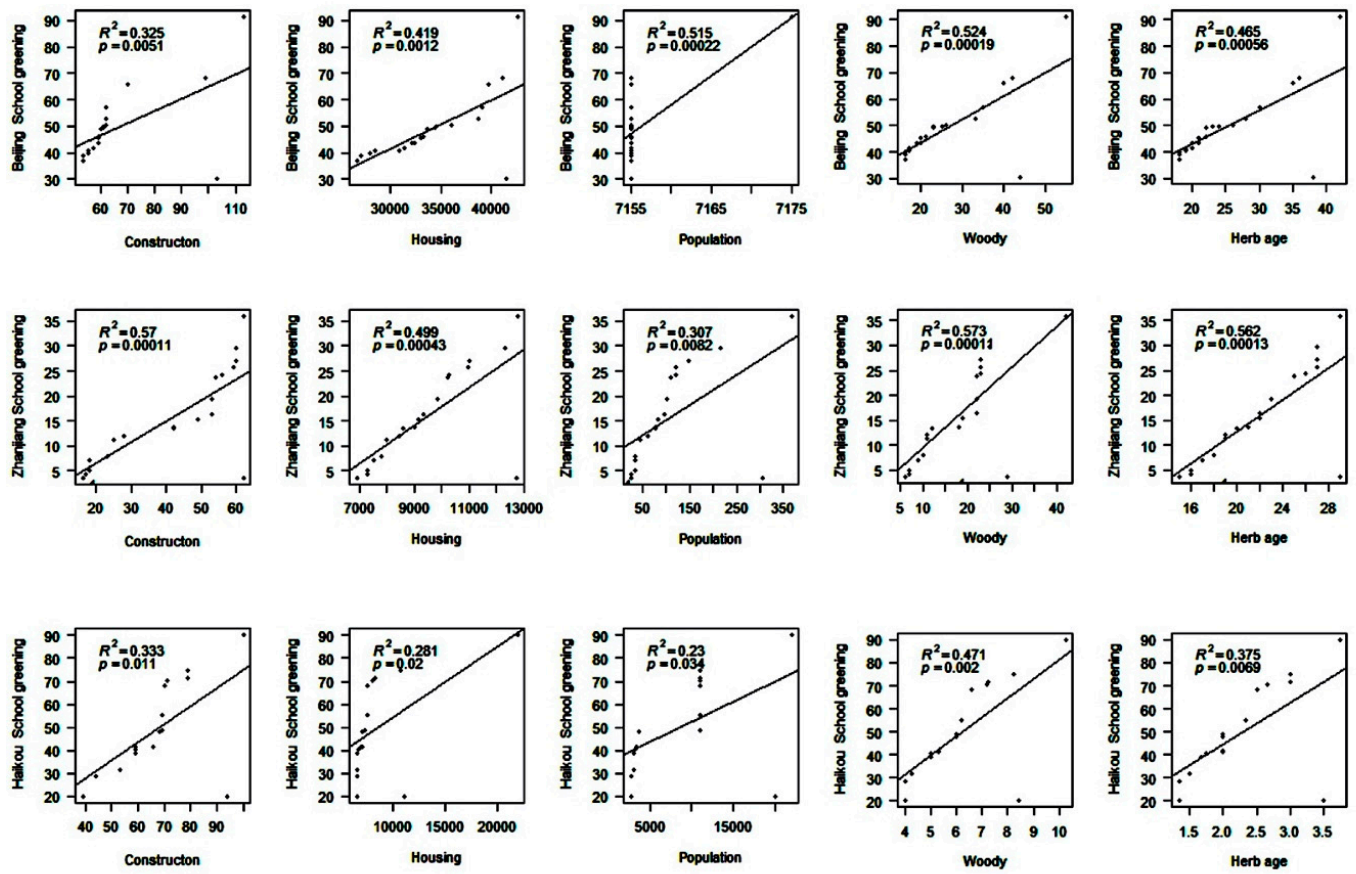

Figure 7. Scatterplots depicting the relationships between the greening percentages of Schools and both socioeconomic variables (construction age, housing price, and population density) and species richness (woody and herbaceous) within Beijing, Zhanjiang, and Haikou. 


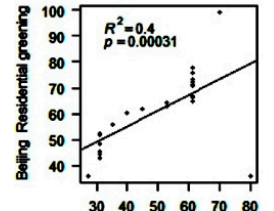

$4050 \quad 60$
Constructon
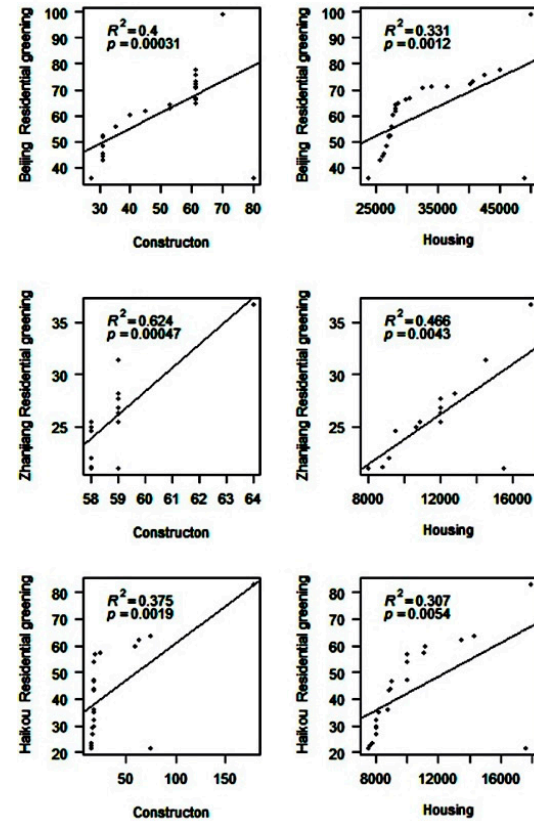

Housing

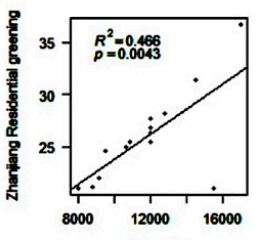

Housing

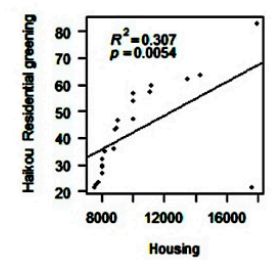

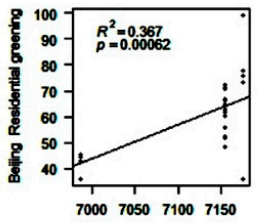

Population

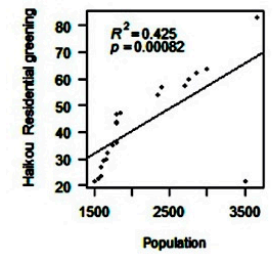

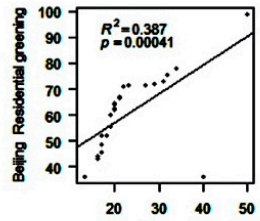

$20 \quad 30$
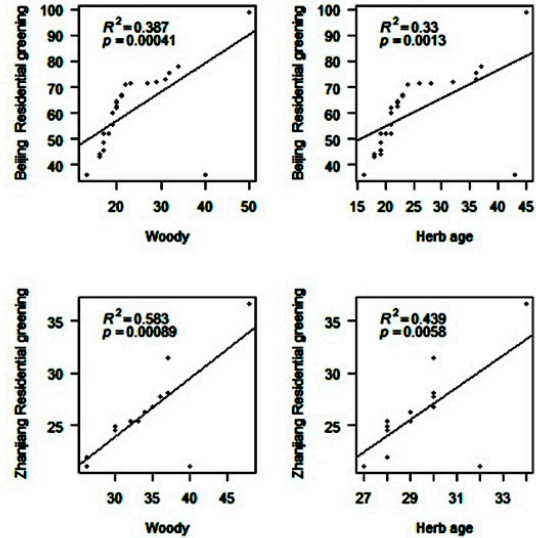

Herb age
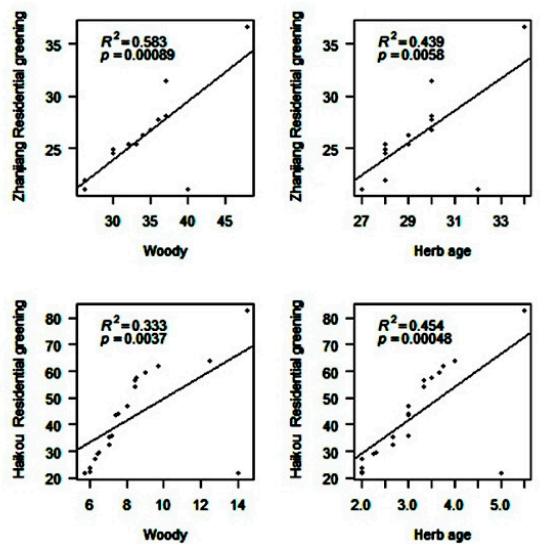

Figure 8. Scatterplots depicting the relationships between the greening percentages of Residential areas and both socioeconomic variables (construction age, housing price, and population density) and species richness (woody and herbaceous) within Beijing, Zhanjiang, and Haikou.

\subsection{Response of Greening Percentage to UFU Characteristics and Maintenance Intensity}

No spatial autocorrelation was found in the three cities. Our models predicted that the greening percentages of the three cities were not correlated with natural predictors such as temperature and precipitation, but that they were significantly correlated with land use cover (Table 3). The greening percentages of all three cities were negatively correlated with impervious area, and positively correlated with forest area in Beijing $\left(R^{2}=0.16, p<0.01\right)$, water area in Haikou $\left(R^{2}=0.01, p=0.13\right)$, and wasteland area in Zhanjiang $\left(\mathrm{R}^{2}=0.13, p<0.01\right)$. In addition, maintenance predictors, such as trimming frequency, were significantly negatively correlated with greening percentage $\left(R^{2}=0.23, p<0.01\right)$. The perimeter of the UFUs was positively correlated with greening percentage in both Beijing $\left(R^{2}=0.02, p<0.01\right)$ and Zhanjiang $\left(\mathrm{R}^{2}=0.12, p<0.01\right)$ (Figure 9).

Table 3. The top models for predicting greening percentage in Beijing, Haikou, and Zhanjiang, China. The $\mathrm{R}$-squared value $\left(\mathrm{R}^{2}\right)$ for each model and the estimated coefficient for each predictor are provided. ${ }^{* * *} p<0.001,{ }^{* *} p<0.01,{ }^{*} p<0.05, \cdot p<0.1$.

\begin{tabular}{cccc}
\hline & Beijing & Haikou & Zhanjiang \\
\hline $\mathrm{R}^{2}$ & 0.49 & 0.61 & 0.68 \\
Intercept & $3.08^{* * *}$ & $2.15^{* * *}$ & $2.76^{* * *}$ \\
Construction period & $0.12^{*}$ & & -0.15 \\
Population density & & & $0.12^{* *}$ \\
Perimeter & $0.02^{* *}$ & & -0.08 \\
The distance from urban center & $0.11^{* *}$ & -0.02 & $0.13^{* *}$ \\
Impervious area & $-0.06^{* *}$ & & 0.13 \\
Wasteland area & -0.07 & $0.13^{* * *}$ & \\
Water area & $0.17^{* * *}$ & & $-0.19^{*}$ \\
Forest area & $0.16^{* * *}$ & -0.26 & $-0.23^{* *}$ \\
Shrub species & & 0.22 & $0.244^{* *}$ \\
Herb species & & & 0.24 \\
Trimming frequency/year & & & $0.14^{*}$ \\
Fertilizing frequency/year & & &
\end{tabular}



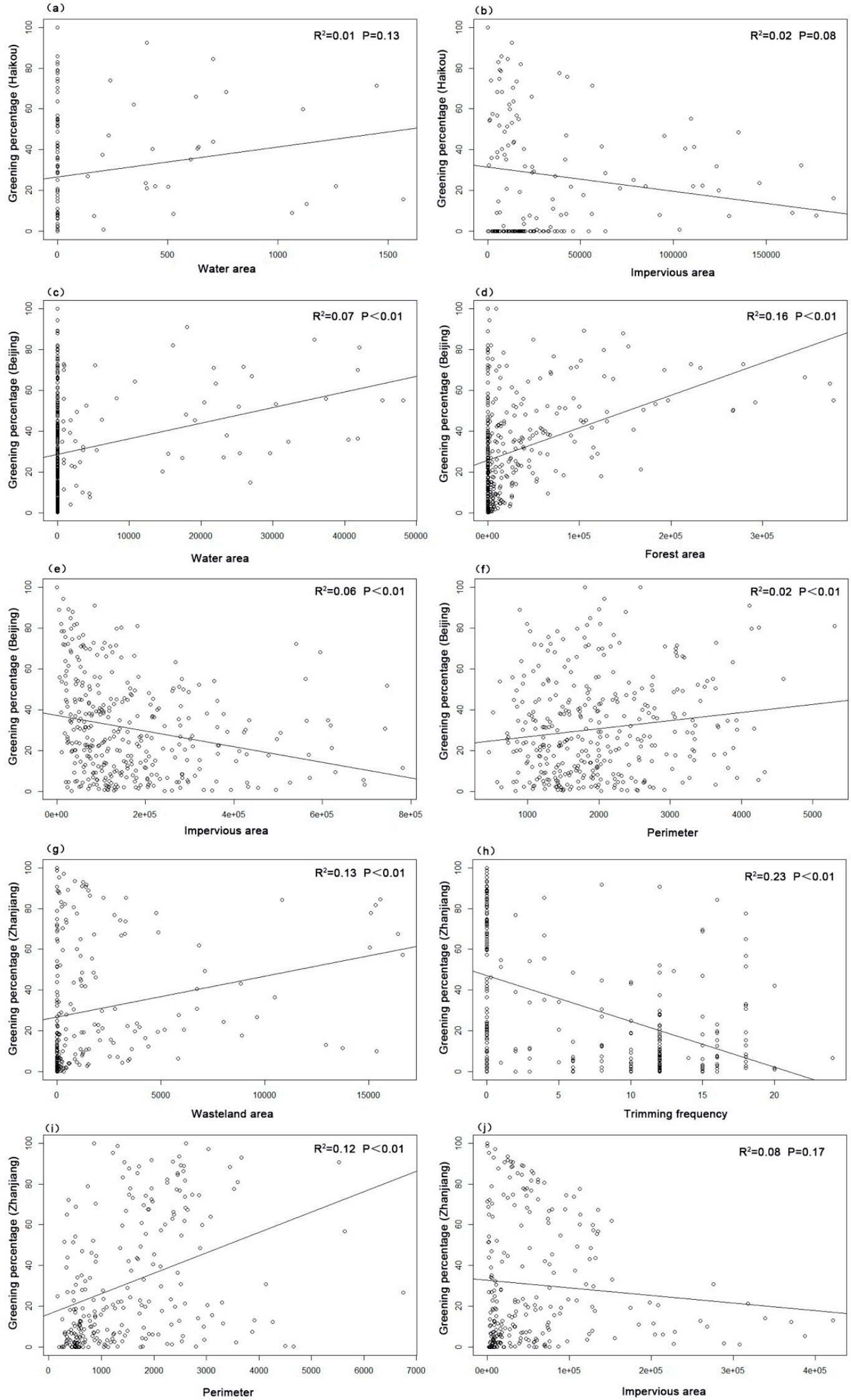

Figure 9. Scatterplots depicting the correlations between greening percentages and impervious area, wasteland area, trimming frequency, and perimeter within Haikou, Beijing, and Zhanjiang. 


\section{Discussion}

\subsection{Variations in the Areas of Primary and Secondary UFUs}

Our results indicated that within the primary UFUs of Beijing, Zhanjiang, and Haikou, Residential areas have the most impervious surface areas while Parks have the most forest, grass, and watery land areas (Figure 2). Within the secondary UFUs of Beijing, Zhanjiang, and Haikou, Colleges/Universities have the most impervious surface area while Parks have the most forest, grass, and watery land areas (Figure 3). These results are similar to those of previous work, which determined the size of primary and secondary UFUs in Beijing [10,13] and Haikou [11].

Two explanations may account for the observed variation between the areas of different primary and secondary UFUs. Firstly, Fang and Zhao [38] stated that this variation may be attributed to discrepancies in methodologies and data sources as well as the particular urban areas included in sampling. To avoid confusion, $\mathrm{Wu}$ [39] proposed a hierarchical system to define urban land with respect to three different levels: impervious area, built-up area, and urban region. We adopted this three-level urban region in this study as we included impervious areas, vegetated areas, barren land, and watery land in our classifications of urban land [40,41]. Although we used these same categories to define urbanized areas in Beijing, Zhanjiang, and Haikou, these classifications may have changed over time and with the occurrence of rapid urbanization; for example, the greening percentage of Beijing, the capital city of China, was $44.99 \%$ in 2005 and is expected to reach $55 \%$ in 2022 [42]. In comparison, the urban greening percentage of Haikou was only $40.6 \%$ in 2017, even though this city harbors more native species than temperate cities.

Secondly, urban planning and policy stimulate urban expansion, thereby increasing capital and population growth and ultimately promoting urban greening $[9,38,43]$. During the 2008 "green Olympic Games" in Beijing, for example, UFUs invested a lot of money into greening measures, such as planting trees and seeding yards. At the end of 1990, there were only three parks in Haikou with a public green area of about $34 \mathrm{hm}^{2}$, an urban greening percentage of $23.7 \%$, and a per capita green area of only $4.35 \mathrm{~m}^{2}$ [44]. In 1995, the Haikou Green Space System was implemented, and in 1997 it began to develop the city's reputation as a National Garden City. These policies effectively controlled green space encroachment, with the total green space area experiencing a reduction of only $333 \mathrm{hm}^{2}$ from 2000 to 2006. Between 1999 and 2006, the number of parks in Haikou increased to 18, built-up area greening percentage increased to $33 \%$, and the number of green patches within built-up areas increased as well [44]. In addition, human disturbance from urban development has led to an increase in the overall number of green patches-specifically green patches with smaller areas. Therefore, the development of national and local government policies is one of the most important driving forces for the changing landscape pattern of Haikou urban green space and may similarly affect the landscape patterns of other cities.

\subsection{Variation in Greening Percentages of Different UFUs}

Like plant diversity in urban areas [23], greening percentages were not greatly affected by environmental factors. In this study, the highest greening percentages were measured within Parks. As one of the most important forms of urban green space, Parks are typically associated with high green cover and greening percentages [45]. The greening percentages of UFUs differed greatly among the three cities; the planning of green infrastructure varies drastically between nations [46], so this observed variation within cities may be attributed to different greening policies. The greening percentage of urban areas was more dependent on impervious area. It has been suggested by many studies that the impervious surface areas within cities seem to decrease overall green area [16,23].

As a temperate inner-land city with a GDP exceeding three trillion yuan in 2018 [33], Beijing has the highest greening percentage in its public squares. This finding indicates that the local government invests more money in public affairs which increase the well-being of citizens and the overall beautification of the city. Tropical coastal cities with more suitable habitat for vegetation 
(e.g., moderate to high temperature and rainfall) can harbor more plant species. Zhanjiang and Haikou have the highest greening percentages within Parks and woodlands despite having lower GDPs (300 and 151 billion Yuan in Zhanjiang and Haikou, respectively) than Beijing. Even though the local governments of Zhanjiang and Haikou have lower budgets for public square greening than Beijing, the climate of both cities enables more native plant species to grow in these regions, thereby increasing the greening percentages of woodlands and Parks. We also noticed that the lowest greening percentage of all UFU types was within Hotels; it is possible that increasing impervious surface area allows for the building of more rooms and parking lots, thereby increasing profits, as suggested by Wang et al. [13].

At the early stage of Haikou urban development in the 1990s, its urban buildings, roads and other infrastructure cut natural vegetation into patches, resulting in the irregular edge shapes of many urban green patches. After the combination of Haikou with Qiongshan city in 2002, the urban areas of Haikou entered a stage of rapid development. Urban green space planning was vigorous, and the reduction of green space was effectively controlled; however, due to the expansion of commercial buildings, residential areas, factories, and other buildings, the shapes of these green spaces became more and more complex [47]. Urban construction was concentrated in the current Haikou Old Town area in the 1990s, and its residential areas became smaller and more dispersed. Around 1992, the Haikou real estate market started expanding, with buildings replacing green space and dominating the urban landscape. By 2006, a large proportion of urban residential areas had been concentrated in coastal regions and the international trade district, and the new residential quarters in the old city had gradually joined to form a larger, continuous residential area. New residential areas tend to pay more attention to the construction of green space, greatly increasing the total green landscape area. With the increasing number of buildings and rising population density the influence of human disturbance on green space is becoming stronger, leading to an increase in the number of small green patches and the overall fragmentation of the green landscape [47].

We found that the greening percentages of all UFUs across all three cities were positively correlated with socioeconomic variables and species richness, which are subsequently suggested as the dominant driving forces of urban green space changes [13,23,48-54]. Wang et al. [55] explained that citizens of residential areas are not directly responsible for local greening practices and plant species richness, instead they hire property management companies to maintain greening and trimming. Wang et al. [55] suspected that companies managing private yards are doing so by the docks as well. This differs from the United States, where $60-70 \%$ of urban land is privately owned, and landscaping, household education, and income levels directly affect plant species richness [50,52,53].

\subsection{The Relationship Between Greening Percentages and Plant Species Richness in Different UFUs Across China}

Greening percentage was significantly positively correlated with both woody and herbaceous species richness across all UFU types and within each of the three cities (Figures 6-8). This result indicates that increased greening percentages in Beijing, Zhanjiang, and Haikou are associated with increased herb and woody species diversity. Wang et al. [13] stated that the green spaces of urban areas are supported by the ground water, and as such they mainly support increased greening by herbs with tap roots rather than fibrous root systems as they have greater success in accessing ground water. Yan et al. [16] suggested that impervious surface area is a key predictor of urban plant diversity during rapid urbanization. In our study, we found evidence of a significant relationship between the greening percentages of UFUs and plant diversity, which may indicate that the areas which we studied are built-up. Future studies on the percentages of impervious surface area within UFUs might reveal a better predictor for urban plant diversity.

We explored the relationships between land cover changes and socioeconomic variables at the UFU level within different cities. Cities are comprised of many different UFUs (e.g., parks, schools, roads, etc.), and these data will be useful for the planning and design of UFUs within a rapidly urbanizing society. When developing UFUs, it is important to consider that the land cover (e.g., the specific plant 
species present) should complement the intended land use; for example, we find there are more edible plant species within lower income residential areas, whereas there are more ornamental plant species in higher income residential areas [10]. Socioeconomic factors provide critical information for urban and landscape planning.

One of the biggest differences between the vegetation in tropical coastal cities and temperate cities is climate. Haikou and Zhanjiang are rapidly developing tropical coastal cities, while Beijing is a rapidly developing temperate inner city. Haikou uses real estate to promote urban expansion along the coast, whereas Beijing displays a circular development which extends to all sides of the city. A previous study reported that the percentage of high-density urban areas in Beijing was significantly correlated with both distance from city center and population density, and that the percentage of urban green spaces decreased exponentially from urban centers to suburbs [10]. The urban development models of Haikou and Beijing are very different (Figures 2 and 5). Investigating these urban greening patterns and plant species composition within cities with different patterns of urban development may provide scientific advice concerning the sustainable development of tropical coastal cities in China.

In this study, we investigated the forces driving urban green space and plant diversity variation across different UFUs. We considered the relationships between land use types (e.g., recreation, education), socioeconomic variables (e.g., housing price, maintenance intensity), and climatic factors (e.g., temperature, humidity). Presently, tropical coastal cities still have considerable area available for urban expansion. Rapid growth within these coastal regions has led to the serious damage of natural vegetation and landscapes on account of the disordered development of real estate. Haikou is in the rapid development period of an international free trade port and in the process of rapid urban development. The relationships identified through this study provide a scientific basis for these efforts. For Haikou, and cities undergoing similar urban development, the layout of green spaces and the selection of vegetation should differ between UFUs on account of land use type and socioeconomic factors.

\section{Conclusions}

Urban functional units (UFUs) are ideal models for analyzing the components of urban ecosystems and powerful grippers for uncovering complex and highly heterogeneous urban ecosystem structures. Different from previous randomly sampling, we can get the land cover and socioeconomic variables at the UFU level and explore the relationships among different components in complex urban ecosystems, for example, Parks represented the largest areas of forest land, grassland, and water bodies in Beijing, Zhanjiang, and Haikou. Moreover, Parks displayed the highest greening percentages of the three UFU types in Zhanjiang and Haikou. The greening percentages of all UFUs across all three cities were positively correlated with socioeconomic variables (e.g., urban population density), indicating that these are dominant forces driving urban green space changes. UFU level analyses are an ideal method to explore the relationships between environmental and socioeconomic variables in complex urban ecosystems. UFUs are the minimum spatial units of urban ecosystems, and socioeconomic and greening management measures are generally homogeneous within them; therefore, we can directly and precisely ascertain the socioeconomic variables driving urban plant diversity changes, which may help to elucidate the drivers of urban greening. Due to the existence of a variety of methods for investigating urban plant diversity, it is hard to compare the data obtained from different studies; however, the methodology of this study may provide an effective way to investigate urban plant diversity within UFUs in individual cities while balancing representative sampling across different cities.

Author Contributions: Conceptualization, H.-F.W. and Z.-X.Z.; methodology, H.-F.W.; software, M.M.N. and L.D.; validation, X.-L.C. and L.J.D.; formal analysis, M.M.N. and X.-L.C.; investigation, H.-F.W. and X.L.C.; resources, H.-F.W.; data curation, M.M.N. and X.-L.C.; writing-original draft preparation, H.-F.W., X.-L.C., M.M.N.; writing一review and editing, H.-F.W., K.B. and S.Q.; visualization, L.J.D.; supervision, H.-F.W.; project administration, H.-F.W.; funding acquisition, L.J.D, H.-F.W., Z.-X.Z. and S.Q. All authors have read and agreed to the published version of the manuscript. 
Funding: This study was funded by the Shanghai Key lab for urban Ecological processes and Eco-Restoration (SHUES2020A07) and a start-up fund from Hainan University [kyqd1633 and kyqd1840 (ZR)].

Acknowledgments: We thank the anonymous reviewers for their constructive comments on this manuscript, and Xiurong Ke for her data analyses help.

Conflicts of Interest: The authors declare no conflict of interest.

\section{References}

1. Li, F.; Wang, R.; Zhao, D. Urban Ecological Infrastructure based on ecosystem services: Status, problems and perspectives. Acta Ecol. Sin. 2014, 34. [CrossRef]

2. Li, J.; Li, C.; Zhu, F.; Song, C.; Wu, J. Spatiotemporal pattern of urbanization in Shanghai, China between 1989 and 2005. Landsc. Ecol. 2013, 28, 1545-1565. [CrossRef]

3. Yang, J.; Yan, P.; He, R.; Song, X. Exploring land-use legacy effects on taxonomic and functional diversity of woody plants in a rapidly urbanizing landscape. Landsc. Urban Plan. 2017, 162, 92-103. [CrossRef]

4. Zhang, D.; Wang, W.; Zheng, H.; Ren, Z.; Zhai, C.; Tang, Z.; He, X. Effects of urbanization intensity on forest structural-taxonomic attributes, landscape patterns and their associations in Changchun, Northeast China: Implications for urban green infrastructure planning. Ecol. Indic. 2017, 80, 286-296. [CrossRef]

5. Masoudi, M.; Tan, P.Y.; Liew, S.C. Multi-city comparison of the relationships between spatial pattern and cooling effect of urban green spaces in four major Asian cities. Ecol. Indic. 2019, 98, 200-213. [CrossRef]

6. Huang, C.; Yang, J.; Jiang, P. Assessing Impacts of Urban Form on Landscape Structure of Urban Green Spaces in China Using Landsat Images Based on Google Earth Engine. Remote Sens. 2018, 10, 1569. [CrossRef]

7. Pickett, S.T.; Zhou, W. Global urbanization as a shifting context for applying ecological science toward the sustainable city. Ecosyst. Health Sustain. 2015, 1, 1-15. [CrossRef]

8. Wu, J. Urban ecology and sustainability: The state-of-the-science and future directions. Landsc. Urban Plan. 2014, 125, 209-221. [CrossRef]

9. Wu, W.J.; Zhao, S.Q.; Zhu, C.; Jiang, J.L. A comparative study of urban expansion in Beijing, Tianjin and Shijiazhuang over the past three decades. Landsc. Urban Plan. 2015, 134, 93-106. [CrossRef]

10. Wang, H.-F.; Qureshi, S.; Qureshi, B.A.; Qiu, J.-X.; Friedman, C.R.; Breuste, J.; Wang, X.-K. A multivariate analysis integrating ecological, socioeconomic and physical characteristics to investigate urban forest cover and plant diversity in Beijing, China. Ecol. Indic. 2016, 60, 921-929. [CrossRef]

11. Zhu, Z.-X.; Pei, H.-Q.; Schamp, B.S.; Qiu, J.-X.; Cai, G.-Y.; Cheng, X.-L.; Wang, H.-F. Land cover and plant diversity in tropical coastal urban Haikou, China. Urban Urban Green. 2019, 44, 126395. [CrossRef]

12. Kremer, P.; Andersson, E.; McPhearson, T.; Elmqvist, T. Advancing the frontier of urban ecosystem services research. Ecosyst. Serv. 2015, 12, 149-151. [CrossRef]

13. Wang, H.-F.; Qiu, J.-X.; Breuste, J.; Ross Friedman, C.; Zhou, W.-Q.; Wang, X.-K. Variations of urban greenness across urban structural units in Beijing, China. Urban Urban Green. 2013, 12, 554-561. [CrossRef]

14. Li, X.; Zhou, W.; Ouyang, Z. Forty years of urban expansion in Beijing: What is the relative importance of physical, socioeconomic, and neighborhood factors? Appl. Geogr. 2013, 38, 1-10. [CrossRef]

15. Fei, W.; Zhao, S. Urban land expansion in China's six megacities from 1978 to 2015. Sci. Total Environ. 2019, 664, 60-67. [CrossRef] [PubMed]

16. Yan, Z.; Teng, M.; He, W.; Liu, A.; Li, Y.; Wang, P. Impervious surface area is a key predictor for urban plant diversity in a city undergone rapid urbanization. Sci. Total Environ. 2019, 650, 335-342. [CrossRef] [PubMed]

17. Groffman, P.M.; Cavender-Bares, J.; Bettez, N.D.; Grove, J.M.; Hall, S.J.; Heffernan, J.B.; Hobbie, S.E.; Larson, K.L.; Morse, J.; Neill, C.; et al. Ecological homogenization of urban USA. Front. Ecol Environ. 2014, 12,74-81. [CrossRef]

18. Liu, H.; Fang, C.; Zhang, X.; Wang, Z.; Bao, C.; Li, F. The effect of natural and anthropogenic factors on haze pollution in Chinese cities: A spatial econometrics approach. J. Clean. Prod. 2017, 165, 323-333. [CrossRef]

19. Da, L.J.; Hang, Y.; Xiaoli, H. The diversity, spatial pattern and dynamic response of Shanghai vegetation in the process of urbanization (VII): Dynamic change and mode optimization of Shanghai Pudong near natural forest in 10 years. J. East China Norm. Univ. Natur. Sci. Ed. 2011, 4, 15-23.

20. SPOT-5 Satellite Sensor. Available online: https://www.satimagingcorp.com/satellite-sensors/other-satellitesensors/spot-5/ (accessed on 12 December 2015). 
21. Wang, H.-F.; Qureshi, S.; Knapp, S.; Friedman, C.R.; Hubacek, K. A basic assessment of residential plant diversity and its ecosystem services and disservices in Beijing, China. Appl. Geogr. 2015, 64, 121-131. [CrossRef]

22. Zhu, Z.-X.; Roeder, M.; Xie, J.; Nizamani, M.M.; Friedman, C.R.; Wang, H.-F. Plant taxonomic richness and phylogenetic diversity across different cities in China. Urban Urban Green. 2019, 39, 55-66. [CrossRef]

23. Hope, D.; Gries, C.; Zhu, W.; Fagan, W.F.; Redman, C.L.; Grimm, N.B.; Nelson, A.L.; Martin, C.; Kinzig, A. Socioeconomics drive urban plant diversity. Proc. Natl. Acad. Sci. USA 2003, 100, 8788-8792. [CrossRef]

24. UFORE (Urban Forest Effects Model). Field Data Collection Manual. 2011. Available online: http://www.ufore. org/using/03-00.html (accessed on 26 April 2020).

25. MacGregor-Fors, I. Misconceptions or misunderstandings? On the standardization of basic terms and definitions in urban ecology. Landsc. Urban Plan. 2011, 100, 347-349. [CrossRef]

26. Cadenasso, M.L.; Pickett, S.T.; Schwarz, K. Spatial heterogeneity in urban ecosystems: Reconceptualizing land cover and a framework for classification. Front. Ecol. Environ. 2007, 5, 80-88. [CrossRef]

27. Walker, J.S.; Blaschke, T. Object-based land-cover classification for the Phoenix metropolitan area: Optimization vs. transportability. Int. J. Remote Sens. 2008, 29, 2021-2040. [CrossRef]

28. Congalton, R.G. A review of assessing the accuracy of classifications of remotely sensed data. Remote Sens. Environ. 1991, 37, 35-46. [CrossRef]

29. Luck, G.W.; Smallbone, L.T.; O'Brien, R. Socio-Economics and Vegetation Change in Urban Ecosystems: Patterns in Space and Time. Ecosystems 2009, 12, 604-620. [CrossRef]

30. Soltanifard, H.; Roshandel, T.; Ghodrati, S. Assessment and ranking of influencing factors in the relationship between spatial patterns of urban green spaces and socioeconomic indices in Mashhad urban districts, Iran. J. Adv. Model. Earth Syst. Environ. 2020, 6, 1589-1605. [CrossRef]

31. Anonymous. Anjuke Housing Price. Available online: http://anjuke.com (accessed on 1 May 2017).

32. Beijing Municipal Bureau of Statistics. Beijing Statistical Yearbook; China Statistics Press: Beijing, China, 2018.

33. Guangdong Bureau of Statistics (GBS). Statistical Yearbook of Guangdong; Guangdong Bureau of Statistics: Guangdong, China, 2014.

34. Hainan Bureau of Statistics (HBS). Statistical Yearbook of Hainan; Hainan Bureau of Statistics: Haikou, China, 2014.

35. Anonymous. Google Earth. Available online: https://www.google.com/earth/ (accessed on 1 May 2017).

36. Venables, W.N.; Ripley, B.D. Modern Applied Statistics with S; Springer: New York, NY, USA, 2002.

37. Paradis, E.; Claude, J.; Strimmer, K. APE: Analyses of phylogenetics and evolution in R language. J. Bioinform. 2004, 20, 289-290. [CrossRef]

38. Fang, C.; Zhao, S. A comparative study of spatiotemporal patterns of urban expansion in six major cities of the Yangtze River Delta from 1980 to 2015. Ecosyst. Health Sustain. 2018, 4, 95-114. [CrossRef]

39. Wu, J. Hierarchy Theory: An Overview. Linking Ecology and Ethics for a Changing World; Springer: New York, NY, USA, 2013; pp. 281-301. [CrossRef]

40. Douglas, I.; Goode, D. Urban natural histories to urban ecologies. The Routledge Handbook of Urban Ecology; Routledge: London, UK, 1994. [CrossRef]

41. McIntyre, N.E.; Knowles-Yánez, K.; Hope, D. Urban Ecology as an Interdisciplinary Field: Differences in the use of "Urban" Between the Social and Natural Sciences. Urban Ecol. 2000, 49-65. [CrossRef]

42. Anonymous. Beijing Greening Percentage. 2005. Available online: http://news.sina.com.cn/c/2005-03-30/ 02205499366s.shtml (accessed on 12 October 2019).

43. Dahal, K.R.; Benner, S.; Lindquist, E. Urban hypotheses and spatiotemporal characterization of urban growth in the Treasure Valley of Idaho, USA. Appl. Geogr. 2017, 79, 11-25. [CrossRef]

44. Wang, F. Launch of green projects to improve the ecological environment-Haikou the creation of a national Garden City has achieved remarkable results. Today Hainan. 1999, 8, 15-16.

45. Wolch, J.R.; Byrne, J.; Newell, J.P. Urban green space, public health, and environmental justice: The challenge of making cities 'just green enough'. Landsc. Urban Plan. 2014, 234-244. [CrossRef]

46. Nock, C.A.; Paquette, A.; Follett, M.; Nowak, D.J.; Messier, C. Effects of urbanization on tree species functional diversity in eastern north America. Ecosystems 2013, 16, 1487-1497. [CrossRef]

47. Fu, H.; Xu, X.S.; Fu, G. Study on Dynamic Changes of Green Space Landscape Pattern in Haikou. J. Fujian For. Sci. Tech. 2015, 42, 142-146.

48. Iverson, L.R.; Cook, E.A. Urban forest cover of the Chicago region and its relation to household density and income. Urban Ecosyst. 2000, 4, 105-124. [CrossRef] 
49. Escobedo, F.J.; Nowak, D.J.; Wagner, J.E.; De la Maza, C.L.; Rodríguez, M.; Crane, D.E.; Hernández, J. The socioeconomics and management of Santiago de Chile's public urban forests. Urban Urban Green. 2006, 4, 105-114. [CrossRef]

50. Grove, J.M.; Troy, A.R.; O’Neil-Dunne, J.P.M.; Burch, W.R.; Cadenasso, M.L.; Pickett, S.T.A. Characterization of Households and its Implications for the Vegetation of Urban Ecosystems. Ecosystems 2006, 9, 578-597. [CrossRef]

51. Kirkpatrick, J.B.; Daniels, G.D.; Zagorski, T. Explaining variation in front gardens between suburbs of Hobart, Tasmania, Australia. Landsc. Urban Plan. 2007, 79, 314-322. [CrossRef]

52. Troy, A.R.; Grove, J.M.; O’Neil-Dunne, J.P.M.; Pickett, S.T.A.; Cadenasso, M.L. Predicting Opportunities for Greening and Patterns of Vegetation on Private Urban Lands. J. Environ. Manag. 2007, 40, 394-412. [CrossRef] [PubMed]

53. Boone, C.G.; Cadenasso, M.L.; Grove, J.M.; Schwarz, K.; Buckley, G.L. Landscape, vegetation characteristics, and group identity in an urban and suburban watershed: Why the 60s matter. Urban Ecosyst. 2009, 13, 255-271. [CrossRef]

54. Szantoi, Z.; Escobedo, F.; Wagner, J.; Rodriguez, J.M.; Smith, S. Socioeconomic factors and urban tree cover policies in a subtropical urban forest. Gisci. Remote Sens. 2012, 49, 428-449. [CrossRef]

55. Wang, H.F.; López-Pujol, J. Urban green spaces and plant diversity at different spatio-temporal scales: The example of Beijing, China. Collect. Bot. 2015, 34, e008. [CrossRef]

(C) 2020 by the authors. Licensee MDPI, Basel, Switzerland. This article is an open access article distributed under the terms and conditions of the Creative Commons Attribution (CC BY) license (http://creativecommons.org/licenses/by/4.0/). 